\title{
Herbal medicine use is frequent in ambulatory surgery patients in Vancouver Canada
}

\author{
[L'usage de plante médicinale est fréquent chez les patients de chirurgie \\ ambulatoire à Vancouver, Canada]
}

Pamela H. Lennox MRCPI FCARCSI, Cynthia L. Henderson MD FRCPC

Purpose: To determine the incidence and nature of herbal medicine use among patients in a busy Canadian surgical day care unit.

Methods: We undertook a prospective survey of 575 patients attending our surgical day care unit. The questionnaire inquired as to basic demographics, herbal medicine use, the name and number of herbal medicines used, reason, whether it was self prescribed or not, and if the patient's family physician was aware of the use. In the second part of the study, 44 anesthesiologists were asked to answer a questionnaire of 27 yes/no questions to determine their knowledge of herbal medicines.

Results: Four hundred eighty-five of 575 patients completed the questionnaire (84\%). Thirty-four percent of patients surveyed in our unit responded affirmatively to herbal medicine use. Of these, $39 \%$ took them on a daily basis. Forty-five different identifiable herbs were being taken in total, with echinacea being the most common. Less than half of the patients told their family physicians that they were using herbal medicines and only one-third of patients were taking them on the advice of their physician. In the assessment of anesthesiologists' knowledge of herbal medicine, only $32 \%$ of the questions were answered correctly.

Conclusion: The incidence of herbal medicine ingestion by patients coming to our unit was higher than previously reported. A large variety of preparations were being taken, many without the knowledge of the patient's family physician. The basic knowledge of anesthesiologists with respect to herbal medicine is limited.

Objectif : Déterminer l'incidence et la nature des plantes médicinales utilisées par les patients d'une unité canadienne de chirurgie d'un jour très occupée.

Méthode : Nous avons réalisé une enquête prospective auprès de 575 patients traités à notre unité de chirurgie d'un jour. Le questionnaire recherchait les caractéristiques de base des patients, l'usage de plante médicinale, le nom et le nombre de plantes utilisées ainsi que la raison de leur emploi. On demandait si elles avaient été prescrites ou non et si le médecin de famille du patient était au courant de leur usage. Dans la seconde partie de l'étude, 44 anesthésiologistes ont répondu à un questionnaire de 27 questions par oui ou non pour tester leur connaissance des plantes médicinales.

Résultats : Quatre cent quatre-vingt-cinq (485) des 575 patients ont rempli le questionnaire (84\%). Trente-quatre pour cent des patients enquêtés ont répondu avoir utilisé des plantes médicinales. Parmi eux, $39 \%$ les prenaient quotidiennement. Quarante-cinq plantes différentes et identifiables étaient prises dont l'échinacée surtout. Moins de la moitié des patients avaient mis leur médecin de famille au courant et seulement un tiers suivait un avis de leur médecin. Les anesthésiologistes n'ont fourni que $32 \%$ de réponses correctes au questionnaire sur les plantes médicinales.

Conclusion : L'incidence de prise de plantes médicinales par les patients fréquentant notre unité de chirurgie ambulatoire a été plus élevée que prévu. Une grande variété de préparations a été prise dont beaucoup n'étaient pas connues du médecin de famille du patient. Les connaissances de base des anesthésiologistes sur les plantes médicinales sont limitées.

From the Department of Anesthesia, University of British Columbia, Vancouver, British Columbia, Canada.

Address correspondence to: Dr. Cynthia Henderson, Department of Anesthesia, Vancouver General Hospital, 855 West $12^{\text {th }}$ Avenue,

Vancouver BC V5Z 1M9, Canada. Phone: 604-875-4304; Fax: 604-875-5209; E-mail: chenders@vanhosp.bc.ca

Accepted for publication March 4, 2002.

Revision accepted September 9, 2002.

CAN J ANESTH 2003/50: 1/pp 21-25 
TABLE Myriad of identifiable herbal medicines

\begin{tabular}{llll}
\hline Acidophilus & Chlorophyll & Fenugreek & Kava \\
Aloe vera & Cod liver oil & Feverfew & Kayam churna \\
Arnica & Cranberry & Flax seed oil & Kelp \\
Astragulus & Devil's claw & Garlic & Lysine Salmon oil \\
Bee pollen & Don quoi & Ginko biloba & Milk thistle \\
Black cohosh & Echinacea & Ginseng & MSM \\
Cat's claw & Ephedra & Glucosamine & Nin jiom \\
Chinese mix & Essiac & Goldenseal & Noni juice \\
Chondroitin & Eucalyptus & Hawthorne & Trimrose oil \\
\hline
\end{tabular}

Many patients are unaware of the potential for side effects or withdrawal syndromes associated with commencing or discontinuing these treatments. Commonly used herbal preparations thought to be innocuous may be associated with significant drug interactions. ${ }^{3-6}$

Not only does some danger lie in taking these remedies themselves, but also in the fact that a number of patients do not inform their family physician that they are taking them. Even more importantly, since herbal medicine pharmacology was not included in the medical school curriculum when most physicians trained, few physicians are aware of the pharmacology of these medications, let alone the specific side-effects and drug interactions associated with their use.

In the United States, between 22 and 26\% of preoperative surgical patients report the use of herbal remedies. ${ }^{7,8} \mathrm{We}$ designed a survey concerning the use of herbal medicine in order to evaluate the current consumption profile of ambulatory surgery patients in a busy Canadian surgical day care unit.

\section{Methods}

Five hundred seventy-five questionnaires concerning herbal medicine use were distributed to patients while awaiting their surgery in the surgical day care unit of Vancouver General Hospital. This was a survey of convenience carried out over a two-month period. The questionnaire was available in English and Chinese, in an effort to include the large population of nonEnglish speaking Chinese patients in Vancouver. Information for the study was obtained from a simple, anonymous one-page questionnaire, which included basic demographic details and then asked if the patient was presently using or had ever used herbal preparations. If patients answered affirmatively, they filled out the remainder of the questionnaire, which included the following information: number of medications, name of medications, frequency of use, reason for use, and if their family physician had prescribed it or was aware that the patient was taking it. A copy of the questionnaire for patients is available at www.cjajca.org as "additional material".

Excluded from the survey were patients who did not understand the questionnaire, including mentally challenged patients and those who did not understand written English or Chinese and had no interpreter available.

Data was analyzed primarily into simple percentages and an analysis of regression was conducted to test whether any of the demographic variables were predictive of herbal use.

In the second part of the study, we conducted a survey of the 44 teaching-hospital anesthesiologists affiliated with our surgical day care unit to determine their knowledge of herbal medicines. A single page questionnaire asked three questions about nine different herbal remedies, for a total of 27 yes/no answers. The data from this survey are presented as simple percentages. A copy of the questionnaire for anesthesiologists is available at www.cja-jca.org as "additional material".

\section{Results}

Four hundred eighty-five of $\mathbf{5 7 5}$ patients completed and returned the questionnaire for a response rate of $84 \%$. Demographic details reflected the normal demographic distribution of our surgical day care unit with 331 female $(68 \%)$ and 154 male $(32 \%)$ respondents. Breakdown of race of the respondents was 308 Caucasian (64\%), 79 Asian (16\%), 35 East Indian (7\%), eight Hispanic (1.6\%), three African American $(0.6 \%)$, and 44 others $(9 \%)$.

One hundred sixty-two of the 485 respondents answered affirmatively to using herbal medication $(34 \%)$. Broken down by gender, 116 of 331 female respondents $(35 \%)$ and 46 of 153 male respondents (30\%) use herbal medication $(P=0.41)$. The ingestion of herbal medicines was similar in the Asian and Caucasian respondents (38\% vs 35\% respectively).

Frequency of herbal medicine use was as follows: daily by 63 patients (39\% of herbal medicine users), once a 


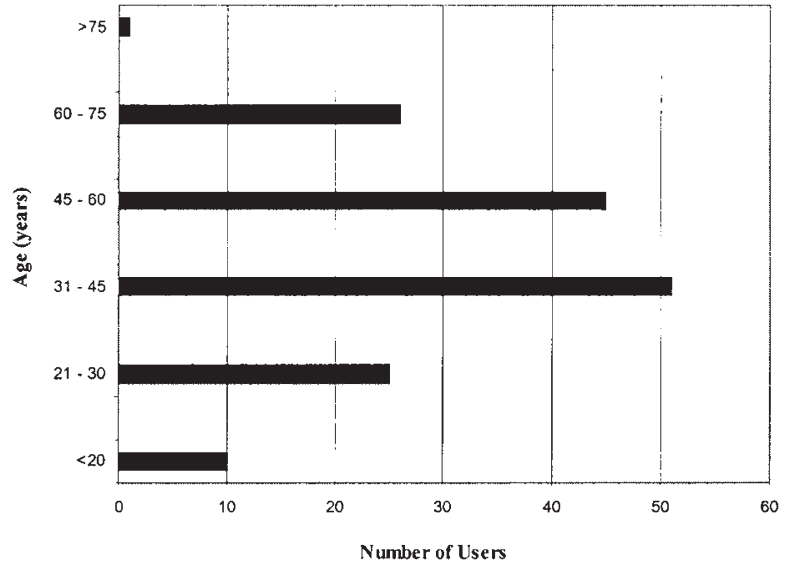

FIGURE 1 Age range of herbal medicine users.

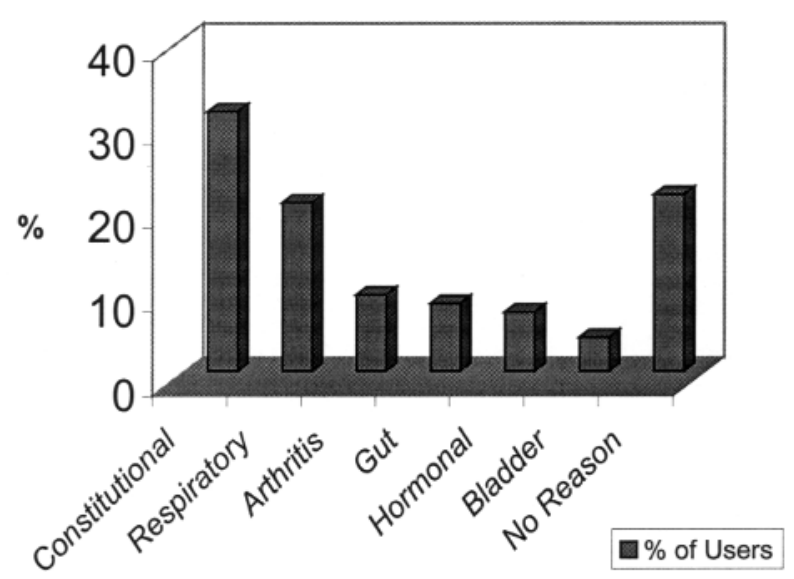

Ailments

FIGURE 2 Reasons for herbal medicine use.

week by 16 patients (10\%), once a month by 20 patients (12\%) and less than once a month by 48 patients $(30 \%)$. Twelve percent of patients taking herbal medication used more than two different herbal medicines daily and 7\% used more than three herbal medicines daily.

Our patients were taking 65 different preparations containing at least 45 distinct ingredients (Table). The most frequent herbal medicine consumed was echinacea, with glucosamine, garlic, ginko biloba, St. John's wort and "chinese mix" (see Discussion) also common. Thirty-five patients $(22 \%)$ did not know the name of the medication they were taking.

The ages of the herbal medicine users are presented in Figure 1. The largest number of consumers of herbal medicines $(31.5 \%$ of users) were in the $31-45$-yr-old range, which was also our largest group of patients. The $46-60$-yr-old group accounted for $25 \%$ of overall use and the over- 60 group in our institution accounted for $17 \%$.

The reasons for taking herbal medicines were diverse, including constitutional symptoms, respiratory complaints, arthritis, gastrointestinal disorders, hormonal and bladder symptoms in decreasing order of frequency (Figure 2).

Seventy-four patients (46\%) had informed their family physician that they were on herbal medicines, while 72 patients $(44 \%)$ stated that their family physician was unaware that they were taking these medications. Of the 162 patients using herbal medicines, 54 were taking them on the advice of their doctor $(33 \%)$ and 88 were self-prescribing (54\%).

When logistic regression was applied to the data, only two variables were marginally significantly predictive of herbal medicine use: Asian race, and age 46-60 yr. No other variables were associated with the use of herbal medicine.

In the second part of the study, 28 of 44 anesthesiologists completed and returned the questionnaire concerning their knowledge of herbal medications (64\% response rate). Of the 27 questions, only $32 \%$ were answered correctly and $52 \%$ were answered "don't know". Many of the responding anesthesiologists admitted that they had guessed at the yes/no answers.

\section{Discussion}

Herbal medicine use is common with $34 \%$ of ambulatory patients attending the surgical day care unit of Vancouver General Hospital taking herbal medication of some type. This is higher than previously reported by Tsen et al., with $22 \%$ of presurgical patients at Brigham and Women's Hospital using herbal medication, ${ }^{7}$ and Leung et al. in California, with $26 \%$ of preoperative non-cardiac patients using herbal medication. ${ }^{8}$ We specifically did not ask about vitamin use, which presumably would have increased our incidence further. We hypothesized that the Asian population might have an increased incidence of herbal medicine use because of the strong tradition of alternative medicine, but Asian race was only marginally predictive of herbal medicine use in our patients.

Our patients were taking 65 different preparations containing at least 45 distinct ingredients. Some of the preparations contained more than three separate ingredients marketed under a single name, making it difficult to determine exactly what the patient was taking with- 
out doing an extensive search. It is disturbing that $22 \%$ of our patients taking herbal medicines did not know the name of the herb ingested. This problem has been recognized previously by Kassler et al. who reported that $24 \%$ of HIV-infected patients taking herbal products were unable to identify the herb that they had used. ${ }^{9}$ Some patients do not know the name of their prescription medications either, but there are many sources of this information including prescriptions, pill bottles, their family physicians and pharmacies.

None of the patients taking a Chinese mix had any idea as to what the mix contained. The ingredients can be quite difficult to determine, since each Chinese herbalist has his/her own recipe. Aconite, an herbal derivative of $\mathrm{Fu} \mathrm{Zi}$, is the commonest cause of adverse effects among Chinese herbal preparations, ${ }^{10}$ however it is not always easy to determine which of a possible 19 different herbs in a mix is at fault. A case of aconite-related left ventricular failure from Chinese herbal medicine in a patient with aortic regurgitation has been reported. ${ }^{11}$

Products vary in the content and quantity of active ingredients as Cui $e t$ al. demonstrated in their analysis of 44 different brands of ginseng. ${ }^{12}$ The quantity of active ingredient was zero in six brands, and ranged from $1.9 \%$ to $9.0 \%$ in the remaining brands tested. ${ }^{12}$

Commonly used herbal preparations thought to be innocuous may be associated with clinically important drug interactions. For example, aloe vera ingestion can enhance the hypoglycemic effect of glibenclamide. ${ }^{3}$ St. John's wort has been reported to prolong emergence from anesthesia ${ }^{4}$ and it may interact with cyclosporine resulting in transplant graft rejection. ${ }^{5}$ The withdrawal from prolonged use of valerian, a sedative-hypnotic herb, can mimic that of a benzodiazepine withdrawal syndrome. ${ }^{6}$

Less than half of our respondents told their family physician that they were taking herbal medications. In a study by Kaye et al., more than $70 \%$ of patients failed to reveal their use of herbal medicine during routine preoperative questioning. ${ }^{13}$ The reasons for this were diverse, including a perceived medical ignorance about herbal medicines, not wanting to admit to 'alternative medicine use', the failure to recognize the significance of these preparations as medicines, and the attitude that it was none of the doctor's business. ${ }^{14}$

Do physicians and, in particular, anesthesiologists actually know much about the significance of these herbal medicines? What is the point of patients reporting herbal medicine use if anesthesiologists are not aware of the clinical importance of these preparations, as we found in the second part of our study?

There is no mention of herbal medicines in the 2001 Canadian Anesthesiologists' Society (CAS) guidelines to the practice of anesthesia, nor is there any information on the CAS website (www.cas.ca). In Canada, the Health Product and Food Branch Directorate of the government of Canada (originally the Therapeutic Products Programme TPP) has established a working party, the Natural Health Products Directorate (NHPD), in order to provide some framework and monitoring for these products in the future. Unfortunately, it does not contain any information relevant to anesthesia at this time.

(http://www.hc-sc.gc.ca/hpb/onhp/clinical_trials_framework_l_e.html).

The American Society of Anesthesiologists takes no formal position on the standard of care with respect to herbal medicines nor does it have a position on the therapeutic properties of herbal medicines. They have published a short document containing limited information called 'What You Should Know About Your Patients' Use of Herbal Medicines', which does not include any specific practice guidelines (www.ASAhq.org).

Although detailed information concerning herbal medications and the potential for interactions with anesthesia is beyond the scope of this article, it should be reviewed by all practicing anesthesiologists. An informative and recent review by Ang-Lee et al. identifies the eight most commonly used herbal medications, then describes their adverse effects, pharmacodynamics, pharmacokinetics, and the implications of each for anesthesiologists. ${ }^{15}$ In addition, the book "Evidence-Based Herbal Medicine" 16 is a useful and current resource.

Even though the survey represents only a sample of our preoperative ambulatory surgery patients, the response rate of $84 \%$ suggests that the results are representative of our population. However, the results may have been biased by those patients who did or did not complete the questionnaire. A greater number of respondents may have responded affirmatively if we had listed the names of different medicines, such as aloe vera, witchhazel, tea-tree oil, garlic, and salmon oil, since some respondents may not have considered them herbal medicines. There may also be some overlap between herbal medicines and vitamins, which were not specifically included in our survey.

In summary, use of herbal medicine by ambulatory surgery patients in Vancouver is common. With such widespread consumption of herbal medicine among preoperative patients, anesthesiologists need to include herbal medicines in their preoperative assessment. Anesthesiologists should review these medications in order to recognize the potential for associated interactions and complications in patients periopera- 
tively. Patients also need to take responsibility for the consequences of herbal medicine use, particularly if they have self-prescribed but not informed their physician. While we should respect the diversity of traditional and alternative medicine, we must ensure that combining herbal medicine with Western medicine is not detrimental to the health of the patient.

\section{References}

1 Eisenberg DM, Davis RB, Ettner SL, et al. Trends in alternative medicine use in the United States, 1990-1997. JAMA 1998; 280: 1569-75.

2 Dietary Supplement Health and Education Act October 25, 1994 (DHSEA) U.S. Public Law 103-417.

3 Okyar A, Can A, Akev N, Baktir G, Sutlupinar N. Effect of aloe vera leaves on blood glucose level in type I and type II diabetic rat models. Phytother Res 2001; 15: 157-61.

4 Crowe S, McKeating K. Delayed Emergence and St. John's wort. Anesthesiology 2002; 96: 1025-7.

5 Moschella C, Jaber BL. Interaction between cyclosporine and Hypericum perforatum (St. John's wort) after organ transplantation. Am J Kidney Dis 2001; 38: 1105-7.

6 Garges HP, Varia I, Doraiswamy PM. Cardiac complications and delirium associated with valerian root withdrawal. JAMA 1998; 280: 1566-7.

7 Tsen LC, Segal S, Pothier M, Bader AM. Alternative medicine use in presurgical patients. Anesthesiology 2000; 93: 148-51.

8 Leung JM, Dzankic S, Manku K, Yuan S. The prevalence and predictors of the use of alternative medicine in presurgical patients in five California hospitals. Anesth Analg 2001; 93: 1062-8.

9 Kassler WJ, Blanc P, Greenblatt R. The use of medicinal herbs by human immunodeficiency virus-infected patients. Arch Intern Med 1991; 151: 2281-8.

10 Tai YT, But PP, Young K, Lau CP. Cardiotoxicity after accidental herb-induced aconite poisoning. Lancet 1992; 340: 1254-6.

11 Wong HCG. Cardiac adverse reaction associated with Fu $\mathrm{Zi}$ : a case of mild aconite poisoning from Chinese herbal medicine. Annales CRMCC 2001; 34: 358-61.

12 Cui J, Garle M, Eneroth P, Bjorkhem I. What do commercial ginseng preparations contain? (Letter). Lancet 1994; 344: 134.

13 Kaye AD, Clarke RC, Sabar R, et al. Herbal medicines: current trends in anesthesiology practice-a hospital survey. J Clin Anesth 2000; 12: 468-71.

14 Eisenberg DM, Kessler RC, Van Rompay MI, et al. Perceptions about complementary therapies relative to conventional therapies among adults who use both: results from a national survey. Ann Intern Med 2001; 135: 344-51.

15 Ang-Lee MK, Moss J, Yuan CS. Herbal medicines and perioperative care. JAMA 2001; 286: 208-16.

16 Rotblatt M, Ziment I. Evidence-Based Herbal Medicine. Philadelphia: Hanley and Belfus Inc.; 2002. 